\title{
STRATEGI PENGEMBANGAN PERKEBUNAN KELAPA DALAM (Cocos nucifera Linn) SEBAGAI KOMODITI UNGGULAN DI KABUPATEN INDRAGIRI HILIR
}

\section{Strategy for Development Coconut Plantation (Cocos nucifera Linn) as a Potential Commodities in Indragiri Hilir Regency}

Sisca Vaulina dan Hajry Arief Wahyudy

Fakultas Pertanian Universitas Islam Riau. Jl. Kaharuddin Nasution 113, Pekanbaru 28284 Riau Telp.: 0761-72126 ext. 123, Fax: 0761-674681

[Diterima: Februari 2018; Disetujui April 2018]

\begin{abstract}
The plantation subsector was an active role to improve region economics in Indragiri Hilir Regency. This study aims to know the multiplier effect of a coconut plantation in Indragiri Hilir Regency, develop concepts and strategies for plantation development as a potential commodity in Indragiri Hilir Regency. The study used survey methods and 9 people collected as key informants, namely community leaders and coconut landowners, extension officers, and coconut farmers. Data analyzed: Multiplier effect and SWOT. The results indicated that the income of multiplier coconut plantation in 2010-2016 had fluctuated value. From the last seven years, the highest value occurred in 2011 values 1.931. Revenues obtained from the base activities coconut plantation base would increase the income of non-base activities. Base activities (coconut plantations) had the power to encourage regional economic growth. Coconut plantation in Indragiri Hilir Regency was in Quadrant III. which means coconut although it has weaknesses still has considerable opportunities to develop. However, it has the opportunity greatly to be developed. One of the methods was too minimal coconut problems to get better market opportunities. The strategy that must be applied is to encourage turn around strategy.
\end{abstract}

Keywords: Coconut, Multiplier Effect, SWOT

\begin{abstract}
ABSTRAK
Subsektor perkebunan dapat berperan aktif dalam rangka peningkatan perekonomian wilayah di Kabupaten Indragiri Hilir. Penelitian ini bertujuan untuk: (1) Mengetahui multiplier effect dari tanaman perkebunan di Kabupaten Indragiri Hilir, (2) Menyusun konsep dan strategi pengembangan perkebunan berbasis komoditi unggulan di Kabupaten Indragiri Hilir. Penelitian ini menggunakan metode survei. Metode pengambilan sampel dilakukan secara sensus, responden pada penelitian ini berjumlah 9 orang sebagai keyinforman yaitu tokoh masyarakat yang sekaligus memiliki kebun kelapa, petugas penyuluh lapangan dan petani kelapa. Analisis data menggunakan Multiflier effect dan SWOT. Hasil penelitian menunjukkan bahwa pengganda pendapatan Kelapa Dalam pada tahun 2010-2016 nilai multiplier effect Kelapa Dalam berfluktuasi. Dari tujuh tahun terakhir, nilai tertinggi terjadi pada tahun 2011 dengan nilai 1,931. Pendapatan yang diperoleh dari kegiatan basis Kelapa Dalam pada gilirannya akan menaikkan pendapatan kegiatan non basis. Kegiatan basis (perkebunan Kelapa Dalam) mempunyai kekuatan untuk mendorong pertumbuhan ekonomi wilayah. Kelapa dalam di Kabupaten Indragiri Hilir berada pada Kuadran III yang artinya kelapa dalam meskipun memiliki kelemahan namun masih memiliki peluang yang cukup besar untuk dikembangkan. Salah satu caranya dengan meminimalkan masalah-masalah internal kelapa dalam sehingga dapat merebut peluang pasar yang lebih baik. Maka strategi yang harus diterapkan adalah mendukung strategi turnaround.
\end{abstract}

Kata kunci: Kelapa Dalam, Multiplier Effect, SWOT 


\section{PENDAHULUAN}

Di kabupaten Indragiri Hilir, sektor pertanian memiliki keunggulan dan prospek yang lebih baik untuk dikembangkan dan diharapkan dapat mendorong sektor-sektor lain untuk berkembang.Tanaman perkebunan yang merupakan tanaman perdagangan yang cukup potensial di kabupaten ini ialah kelapa dalam, kelapa hibrida, kelapa sawit, pinang, sagu, kopi, karet dan kakao. Berdasarkan penelitian Vaulina dan Khairizal (2016), kelapa dalam merupakan komoditi unggulan dan layak dikembangkan di Kabupaten Indragiri Hilir.

Berdasarkan kondisi potensi yang ada di Kabupaten Indragiri Hilir, maka mempunyai potensi sumber daya yang cukup memadai sebagai basis keunggulan daerah antara lain berupa; (a) lahan pertanian yang masih tersedia, (b) kesesuaian lahan disetiap kecamatan cocok untuk tanaman perkebunan, (c) adanya industri dan perusahaan, (d) perairan yang luas untuk akses perdagangan, dan (e) sumber daya manusia.

Pada era otonomi daerah saat sekarang, daerah diberi kewenangan dan peluang yang luas bagi pengembangan potensi ekonomi, sosial, politik dan budaya. Salah satu bentuk peluang itu adalah perlunya penajaman orientasi pembangunan yang berbasis pada potensi daerah. Masing-masing daerah didorong tidak saja untuk lebih mampu mengambil peran dalam perencanaan pembangunan, tetapi juga lebih jeli mengeksplorasi dan mengeksploitasi sumber daya yang bertujuan untuk mensejahterakan rakyat setempat (Prawoto, 2010). Untuk itu perlu adanya kebijakan-kebijakan yang dapat merangsang perkembangan wilayah sesuai dengan potensinya masing-masing.

Berdasarkan uraian diatas, maka penelitian ini mencoba mengkaji permasalahan yaitu bagaimana pengembangan perkebunan kelapa dalam berbasis komoditi unggulan di Kabupaten Indragiri Hilir. Adapun tujuan penelitian ini, adalah untuk: (1) Mengetahui multiplier effect kelapa dalam di Kabupaten Indragiri Hilir, (2) Menyusun konsep dan strategi pengembangan perkebunan kelapa dalam berbasis komoditi unggulan di Kabupaten Indragiri Hilir.

\section{METODE PENELITIAN}

Penelitian ini menggunakan metode survei. Survei merupakan penyelidikan yang diadakan untuk memperoleh fakta-fakta dari gejala-gejala yang ada dan mencari keteranganketerangan secara faktual, baik tentang institusi sosial, ekonomi atau politik dari suatu kelompok ataupun suatu daerah (Nazir, 2009). Penelitian dilaksanakan di Kabupaten Indragiri Hilir, metode pengambilan sampel dilakukan secara sensus. Responden pada penelitian ini berjumlah 9 orang sebagai keyinforman yaitu tokoh masyarakat yang sekaligus memiliki kebun kelapa, petugas penyuluh lapangan dan petani kelapa.

Data yang digunakan dalam penelitian ini adalah data sekunder dan data primer. Data sekunder diperoleh dari Dinas Perkebunan Kabupaten Indragiri Hilir, Badan Pusat Statistik Kabupaten Indragiri Hilir. Data sekunder berupa data timeseries tahun 2010-2016 yakni data produksi tanaman perkebunan, produktivitas tanaman perkebunan, luas lahan tanaman perkebunan, dan gambaran umum Kabupaten Indragiri Hilir. Data primer diperoleh dari hasil wawancara dengan tokoh masyarakat, PPL dan petani,dengan cara wawancara yangdibantu oleh daftar pertanyaan (kuesioner). Dalam hal ini informasi atau keterangan diperoleh langsung dari responden dengan cara tatap muka dan bercakap-cakap dengan mengajukan beberapa pertanyaan (key question) yang telah dipersiapkan penulis sebelumnya. Data primer yang dikumpulkan meliputi data tentang variabel-variabel untuk analisis SWOT.

\section{Analisis Data}

(1) Multiplier effect perkebunan kelapa dalam Menghitung nilai pengganda pendapatan subsektor perkebunan digunakan rumus pengganda pendapatan. Masalah paling mendasar pada model ekonomi basis adalah masalah timelag. Hal ini diakui, bahwa penggandaan basis (basemultiplier) tidak berlangsung secara tepat, karena membutuhkan timelag antara respon dari sektor basis terhadap permintaan luar wilayah dan respon dari sektor non-basis terhadap perubahan sektor basis. Pendekatan yang biasanya dilakukan tehadap masalah ini adalah mengabaikan masalah timelag, berdasarkan pernyataan bahwa dalam jangka panjang masalah time lag ini pasti terjadi. Beberapa pakar ekonomi wilayah mencoba mengatasi masalah tersebut dengan memodifikasi rumus penggandaan basis. Penggandaan basis dapat dinyatakan: 
Penggandaan basis

$=\frac{\text { Pendapatan total }}{\text { Pendapatan basis }}$

Pendapatan total

= penggandaan basis $\mathrm{x}$ pendapatan basis ...

Memudahkan pengertian rumus di atas maka digunakan simbol untuk mengganti katakata tersebut, disajikan di bawah ini:

$\mathrm{Y}=$ Pendapatan Total

$\mathrm{YB}=$ Pendapatan Basis

$\mathrm{YN}=$ Pendapatan Nonbasis

$\mathrm{M}=$ Penggandaan Basis

(Budiharsono, 2001)

Berdasarkan penggunaan simbol-simbol tersebut, maka rumus (2) di atas dapat dinyatakan sebagai berikut:

$\mathrm{Y}=\mathrm{M} \times \mathrm{YB}$

Rumus (3) dapat dinyatakan sebagai berikut:

$$
\begin{aligned}
M & =\frac{Y}{Y_{B}}=\frac{Y_{B}+Y_{N}}{Y_{B}} \\
& =\frac{Y_{B}}{Y_{B}}+\frac{Y_{N}}{Y_{B}} \\
& =1+\frac{1}{B S R} \ldots \ldots \ldots
\end{aligned}
$$

Jadi pengganda pendapatan jangka pendek (MS) adalah:

$$
\begin{aligned}
\mathrm{M} & =1+\frac{1}{\mathrm{BSR}} \\
\mathrm{BSR} & =\frac{\mathrm{Y}_{\mathrm{B}}}{\mathrm{Y}_{\mathrm{N}}} \ldots \ldots \ldots \ldots \ldots \ldots \ldots \ldots
\end{aligned}
$$

Keterangan:

$\mathrm{M} \quad=$ Pengganda pendapatan jangka pendek

$\mathrm{Y}_{\mathrm{B}} \quad=$ Pendapatan basis

$\mathrm{Y}_{\mathrm{N}} \quad=$ Pendapatan non basis

(Warpani, 1984)

(2) Menyusun konsep dan strategi pengembangan tanaman perkebunan berbasis komoditi unggulan

Strategi pengembangan tanaman perkebunan berbasis komoditi unggulan digunakan analisis SWOT sebagai alat untuk formulasi strategi. Penyusunan strategi pengembangan dilakukan dengan tiga tahap pelaksanaan. Tahap tersebut meliputi; (1) pengumpulan data, baik data internal dan data eksternal (2) tahap analisis data yang berkaitan dengan komoditi unggulan, (c) tahap penyusunan strategi yang didasarkan pada evaluasi internal dan eksternal sektor dan kemudian akan dilakukan arah kebijakan pengembangan, dan padaakhirnya menemukan program pengembangan. Analisis kondisi daerah pada sektor unggulan dan rekomendasi strategi umum yang bisa dilakukan daerah dalam rangka pengembangan sektor unggulan daerah.

\section{HASIL DAN PEMBAHASAN}

\section{(1) Multiplier Effect Kelapa Dalam}

Menurut konsep ekonomi basis wilayah, pada dasarnya pertumbuhan ekonomi dalam suatu wilayah terjadi karena adanya efek pengganda dari pembelanjaan kembali pendapatan yang diperoleh melalui penjualan barang dan jasa yang dihasilkan wilayah itu yang dipasarkan ke luar wilayah. Besarnya kekuatan efek pengganda tersebut yang mendorong pertumbuhan ekonomi ditunjukkan oleh koefisien pengganda yang dihasilkan (Budiharsono, 2001).

Berdasarkan hasil analisis pengganda pendapatan Kelapa Dalam pada tahun 20102016 nilai multiplier effect Kelapa Dalam berfluktuasi. Dari tujuh tahun terakhir, nilai tertinggi terjadi pada tahun 2011 dengan nilai 1,931. Nilai multiplier effect Kelapa Dalam dapat dilihat pada Gambar 1.

Berdasarkan Gambar 1, koefisien pengganda pendapatan Kelapa Dalam memiliki arti bahwa setiap peningkatan permintaan akhir pada sektor basis perkebunan Kelapa Dalam sebesar Rp 1,00 maka akan memperoleh peningkatan multiplier effect pada sektor non basis sebesar (Rp 0,659) pada tahun 2010, kemudian naik menjadi $\mathrm{Rp} 0,931$ pada tahun 2011, dan turun Rp 0,052 pada tahun 2012, dan turun menjadi (Rp 0,032) pada tahun 2013. Pada tahun 2014, naik menjadi 0,825; dan untuk tahun 2015 dan 2016 turun menjadi 0,066 dan 0,125 . Pendapatan yang diperoleh dari kegiatan basis Kelapa Dalam pada gilirannya akan menaikkan pendapatan kegiatan non basis. Ini membuktikan bahwa kegiatan basis (perkebunan Kelapa Dalam) mempunyai kekuatan untuk mendorong pertumbuhan ekonomi wilayah. 


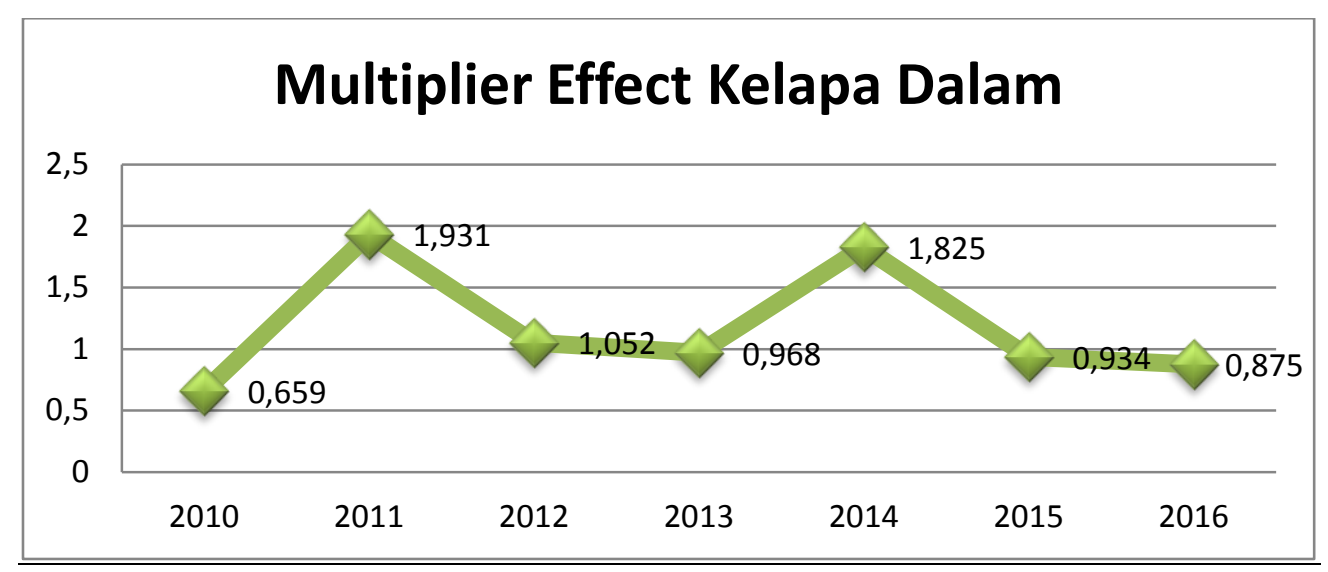

Gambar 1. Koefisien Pengganda Pendapatan Kelapa Dalam, Tahun 2010-2016

Berdasarkan hasil perhitungan dapat dijelaskan bahwa angka pengganda pendapatan jangka pendek sektor Kelapa Dalam memiliki nilai yang besar.Hal ini mengindikasikan bahwa dengan adanya perkebunan Kelapa Dalam dapat memberikan multiplier effect di wilayah ini. Ini terbukti dengan timbulnya industri-industri pengolahan yang berbahan baku Kelapa Dalam. Perkebunan Kelapa Dalam mempunyai efek ganda terhadap ekonomi wilayah terutama sekali dalam industri pengolahan dan produk turunannya (industri hilir). Terhadap masyarakat sekitar, dengan adanya perkebunan Kelapa Dalam terbentuk industri-industri rumah tangga yang berbasis Kelapa Dalam.Hal ini memberikan arti bahwa dengan adanya perkebunan Kelapa Dalam juga memberikan peluang berusaha dan kesempatan kerja bagi masyarakat setempat. Aris dkk (2010), menunjukkan bahwa sektor kelapa dan sektor industri pengolahan kelapa memiliki dampak yang besar terhadap pembentukan output, nilaitambah bruto, dan penyerapan tenaga kerja di Kabupaten Indragiri Hilir.

Penelitian Ruslan (1986) dan Zulgani (1994), koefisien pengganda pendapatan jangka pendek perkebunan Kelapa Dalam pada masingmasing wilayah memberikan angka pengganda pendapatan yang besar, dengan nilai pengganda pendapatan berkisar antara 9,91 hingga 18,97. Sementara itu, koefisien pengganda pendapatan Kelapa Dalam di Kabupaten Indragiri Hilir berkisar antara 2,08 hingga 3,10. Kecilnya nilai koefisien pengganda pendapatan di Kabupaten Indragiri Hilir disebabkan karena adanya perbedaan variabel yang digunakan dalam pemakaian rumus multiplier effect. Pada penelitian sejenis (komoditi Kelapa Dalam) multiplier effect, variabel yang digunakan untuk rumus multiplier effect menggunakan variabel pendapatan wilayah (nilai PDRB Kelapa Dalam). Pada penelitian ini variabel yang digunakan dari metode LQ (jumlah sektor basis dan jumlah sektor basis), sehingga dengan demikian terlihat bahwa berapa besar sektor basis (Kelapa Dalam) mampu meningkatkan kegiatan non basis di Kabupaten Indragiri Hilir.

\section{(2) Strategi Pengembangan Perkebunan Kelapa Dalam}

Dalam pengambilan strategi yang dibutuhkan, terlebih dahulu melakukan analisis SWOT yang dilihat dari faktor eksternal dan faktor internal dari Kelapa Dalam di Kabupaten Indragiri Hilir. Faktor eksternal mencerminkan peluang (opportunity) dan ancaman (threats) yang terjadi pada tanaman kelapa dalam. Faktor internal mencerminkan kekuatan (strength) dan kelemahan (weakness) dari kelapa dalam.

Berdasarkan analisis internal dan eksternal pada tanaman kelapa dalam, maka unsur-unsur yang termasuk ke dalam kekuatan, kelemahan, peluang dan ancaman pada tanaman kelapa dapat dilihat sebagai berikut:

A. Kekuatan (Strength)

Kekuatan merupakan suatu kompetensi yang dapat menangani peluang dan ancaman yang dimiliki oleh suatu organisasi tertentu (Rangkuti, 2009). Kekuatan yang dimiliki tanaman kelapa dalam di Kabupaten Indragiri Hilir yaitu:

1. Kesesuaian lokasi dan iklim tumbuh tanaman kelapa

2. Kelapa mudah tumbuh diberbagai kondisi dibandingkan tanaman lain

3. Ketersediaan tenaga kerja lokal

4. Pengalaman dan pengenalan terhadap kelapa sudah lama

5. Dukungan pemerintah terhadap dengan pengembangan kelapa 
B. Kelemahan (Weakness)

Kelemahan yang terdapat pada kelapa dalam yaitu:

1. Ketersediaan bibit unggul

2. Produktivitas rendah

3. Tanaman kelapa banyak yang sudah tua

4. Harga jual kelapa

5. Peranan tenaga penyuluh

6. Minimnya pemeliharaan tanaman

C. Peluang (Opportunity)

Kesempatan sebagai salah satu unsur eksternal yang berpotensi menguntungkan apabila mampu memanfaatkan peluang (Tripomo, 2005). Peluang yang dimiliki tanaman kelapa yaitu:
1. Kelapa memiliki produk turunan yang masih banyak belum dikembangkan

2. Komoditi ekspor

3. Perluasan tanaman yang masih memungkinkan

4. Pemanfaatan tanaman sela

5. Pemanfaatan limbah kelapa (sabut dan arang)

D. Ancaman (Threats)

Ancaman yang dimiliki tanaman kelapa yaitu:

1. Alihfungsi lahan

2. Luapan air pasang

3. Serangan hama

4. Ketatnya saingan dari beberapa minyak nabati lain

Tabel 1. Internal Factors Analysis Summary (IFAS) Perkebunan Kelapa Dalam di Kabupaten Indragiri Hilir, 2018

\begin{tabular}{|c|c|c|c|c|}
\hline No & Faktor Strategi Internal & Bobot & Rating & Bobot x Rating \\
\hline \multicolumn{5}{|c|}{ Kekuatan } \\
\hline 1 & Kesesuaian lokasi dan iklim tumbuh tanaman kelapa & 0,110 & 4 & 0,440 \\
\hline 2 & $\begin{array}{l}\text { Kelapa mudah tumbuh diberbagai kondisi dibandingkan } \\
\text { tanaman lain }\end{array}$ & 0,113 & 4 & 0,453 \\
\hline 3 & Ketersediaan tenaga kerja lokal & 0,057 & 2 & 0,113 \\
\hline 4 & Pengalaman dan pengenalan terhadap kelapa sudah lama & 0,093 & 3 & 0,280 \\
\hline \multirow[t]{2}{*}{5} & $\begin{array}{l}\text { Dukungan pemerintah terhadap dengan pengembangan } \\
\text { kelapa }\end{array}$ & 0,077 & 3 & 0,230 \\
\hline & Subtotal & $\mathbf{0 , 4 5 0}$ & & 1,517 \\
\hline \multicolumn{5}{|c|}{ Kelemahan } \\
\hline 1 & Ketersediaan bibit unggul & 0,113 & 4 & 0,453 \\
\hline 2 & Produktivitas rendah & 0,090 & 3 & 0,270 \\
\hline 3 & Tanaman kelapa banyak yang sudah tua & 0,083 & 3 & 0,250 \\
\hline 4 & Harga jual kelapa & 0,120 & 4 & 0,480 \\
\hline 5 & Peranan tenaga penyuluh & 0,077 & 3 & 0,230 \\
\hline \multirow[t]{3}{*}{6} & Minimnya pemeliharaan tanaman & 0,067 & 2 & 0,133 \\
\hline & Subtotal & $\mathbf{0 , 5 5 0}$ & & 1,817 \\
\hline & Total & 1,000 & & $\mathbf{3 , 3 3 3}$ \\
\hline
\end{tabular}

Berdasarkan Tabel 1, faktor kekuatan (strength) mempunyai total nilai skor 1,517 dan kelemahan (weakness) 1,817, dengan total skor faktor internal 3,333. Seperti halnya pada tabel IFAS, maka pada faktor-faktor strategis eksternal EFAS juga dilakukan identifikasi yang hasilnya dapat dilihat pada Tabel 2.

Berdasarkan hasil analisis pada Tabel 2, faktor peluang (opportunity) mempunyai nilai skor 1,836 dan ancaman (treaths) mempunyai total nilai skor 0,931 , dengan total nilai skor faktor eksternal 2,767. Selanjutnya, masingmasing fakor intenal dan eksternal memiliki nilai selisih dan akan dibuat ke dalam diagram analisis SWOT (Gambar 2).

Berdasarkan Gambar 2 terlihat bahwa kelapa dalam di Kabupaten Indragiri Hilir berada pada Kuadran III yang artinya kelapa dalam meskipun memiliki kelemahan namun masih memiliki peluang yang cukup besar untuk dikembangkan. Salah satu caranya dengan meminimalkan masalah-masalah internal kelapa dalam sehingga dapat merebut peluang pasar yang lebih baik.Maka strategi yang harus diterapkan adalah mendukung strategi turnaround.

Turn-around dalam hal ini yakni kelapa dalam memiliki kelemahan namun pada saat bersamaan masih punya cukup waktu dan masih ada resources yang memadai untuk mencari solusi. Pada kuadran ini berada dalam tahap krisis, namun masih punya ruang untuk bergerak, khususnya untuk peningkatan produksi kelapa dengan cara menanam tanaman 
baru dan produk turunan kelapa memiliki daya saing. Ada beberapa indikator yang dapat dipakai untuk melihat seberapa jauh kelapa dalam dapat diputar haluannya. Indikator tersebut antara lain:

1. Adanya dukungan pemerintah berupa kebijakan harga kelapa

2. Mendatangkan investor-investor untuk pengembangan tanaman kelapa

3. Mengembangkan produk turunan kelapa berbasis industri rumah tangga

Tabel 2. Eksternal Factors Analysis Summary (EFAS) Perkebunan Kelapa Dalam di Kabupaten Indragiri Hilir, 2018

\begin{tabular}{|c|c|c|c|c|}
\hline No & Faktor Strategi Eksternal & Bobot & Rating & Bobot x Rating \\
\hline \multicolumn{5}{|c|}{ Peluang } \\
\hline 1 & $\begin{array}{l}\text { Kelapa memiliki produk turunan yang masih banyak } \\
\text { belum dikembangkan }\end{array}$ & 0,147 & 4 & 0,586 \\
\hline 2 & Komoditi ekspor & 0,129 & 3 & 0,388 \\
\hline 3 & Perluasan tanaman yang masih memungkinkan & 0,112 & 3 & 0,336 \\
\hline 4 & Pemanfaatan tanaman sela & 0,112 & 3 & 0,336 \\
\hline \multirow[t]{2}{*}{5} & Pemanfaatan limbah kelapa (sabut dan arang) & 0,095 & 2 & 0,190 \\
\hline & Subtotal & $\mathbf{0 , 5 9 5}$ & & $\mathbf{1 , 8 3 6}$ \\
\hline \multicolumn{5}{|c|}{ Ancaman } \\
\hline 1 & Alihfungsi lahan & 0,103 & 2 & 0,207 \\
\hline 2 & Luapan air pasang & 0,091 & 1 & 0,091 \\
\hline 3 & Serangan hama & 0,108 & 3 & 0,323 \\
\hline \multirow[t]{3}{*}{4} & Ketatnya saingan dari beberapa minyak nabati lain & 0,103 & 3 & 0,310 \\
\hline & Subtotal & $\mathbf{0 , 4 0 5}$ & & $\mathbf{0 , 9 3 1}$ \\
\hline & Total & $\mathbf{1 , 0 0 0}$ & & 2,767 \\
\hline
\end{tabular}

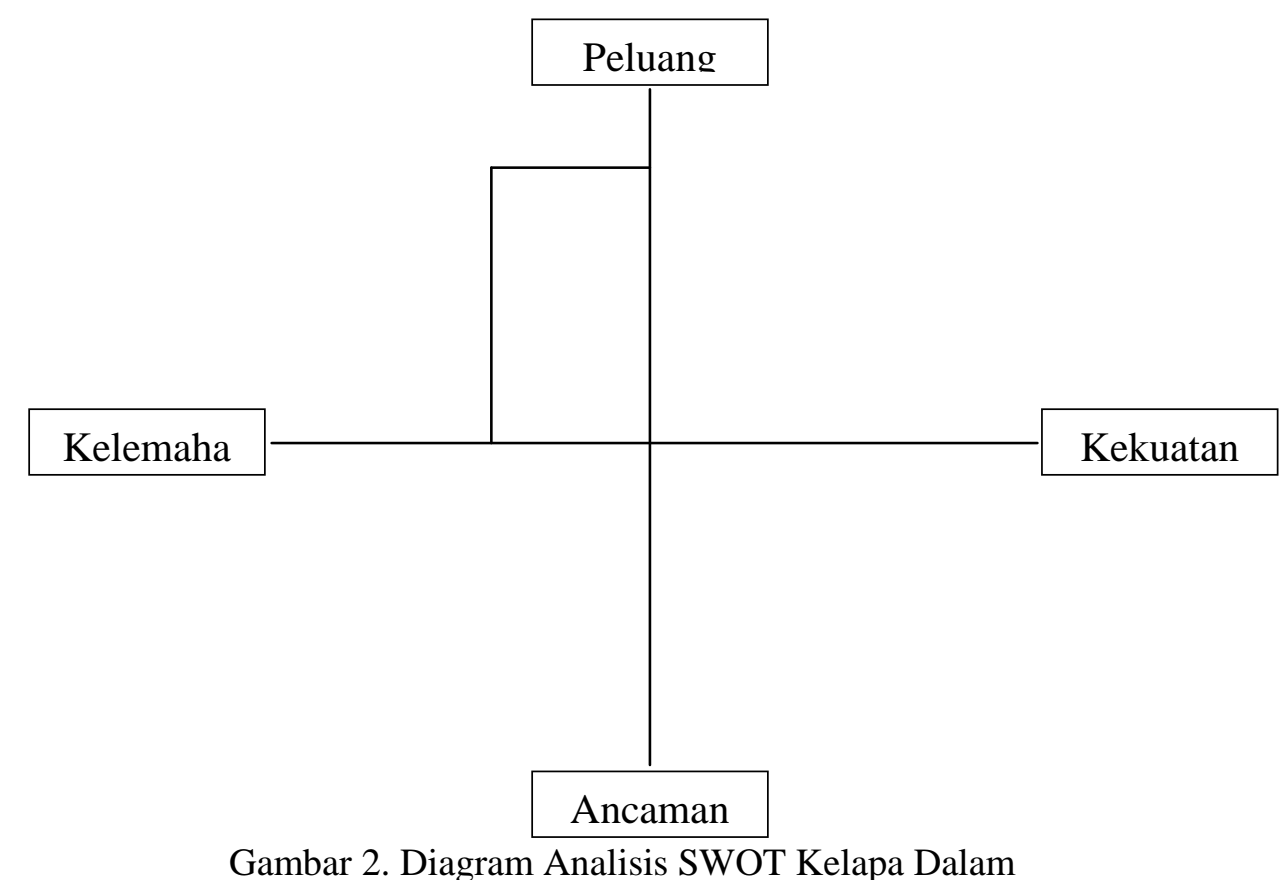

Hasil analisis SWOT di Desa Palolo dan Marawola Pongi et al, (2015) memiliki strategi pengembangan: pemerintah seharusnya memfasilitasi petani berupa pinjaman, pusat informasi dan infrastruktur untuk membantu proses dan pemasaran kelapa. Menurut Damanik (2007) strategi pengembangan sistem agribisnis kelapa di Indragiri Hilir melalui diversifikasi produk melalui pemanfaatan tempurung, sabut dan lidi serta minyak murni (VCO), sehingga dapat merubah permintaan menjadi elastis untuk meningkatkan daya serap pasar serta program promosi pasar di pasar dunia baik melalui lembaga promosi propinsi Riau.

Senada dari hasil penelitian Wardanu dan Anhar (2014) strategi yang direkomendasikan untuk pengembanganagroindustri kelapa di Kabupaten Ketapang yaitu: mempertahankan atau meningkatkan ketersediaan bahan bakumelalui perluasan lahan maupun 
penyediaan bibit yang unggul dantahan hama membangun industri pengolahan kelapa. Kristiana (2014) prioritas strategi dalam pengembangan agribisnis kelapa melalui optimalisasi peremajaan kelapa tua dan diversifikasi usaha produk turunan melalui pengolahan kelapa terpadu baik dalam unit kecil maupun unit besar.

\section{KESIMPULAN}

1. Pendapatan yang diperoleh dari kegiatan basis Kelapa Dalam pada gilirannya akan menaikkan pendapatan kegiatan non basis. Ini membuktikan bahwa kegiatan basis (perkebunan Kelapa Dalam) mempunyai kekuatan untuk mendorong pertumbuhan ekonomi wilayah.

2. Kelapa dalam di Kabupaten Indragiri Hilir berada pada Kuadran III yang artinya kelapa dalam meskipun memiliki kelemahan namun masih memiliki peluang yang cukup besar untuk dikembangkan. Salah satu caranya dengan meminimalkan masalah-masalah internal kelapa dalam sehingga dapat merebut peluang pasar yang lebih baik. Maka strategi yang harus diterapkan adalah mendukung strategi turn-around.

\section{SARAN}

1. Ditinjau dari pangganda pendapatan, perlu didorong pertumbuhan dari sektor yang hasil produksinya dapat dijual ke luar daerah, terutama ekspor ke luar negeri. Oleh sebab itu pemerintah daerah Kabupaten Indragiri Hilir sebaiknya memberikan perhatian khusus dalam pengembangan subsektor perkebunan Kelapa Dalam, yaitu dengan memperluas lahan perkebunan kelapa di kecamatan-kecamatan yang berpotensi untuk tumbuhnya kelapa, terutama di Kecamatan Tempuling, Keritang dan Kemuning.

2. Meningkatkan daya saing Kelapa Dalam dengan melakukan peningkatan produktivitas dan mutu hasil kelapa, memberikan bantuan kepada petani berupa bibit unggul. Sampai saat ini petani kelapa hanya menggunakan bibit yang berasal dari pohon induk kelapa yang sudah ada di lahan usahataninya.

\section{DAFTAR PUSTAKA}

Aris, A., Bambang Juanda, Akhmad Fauzi, dan Dedi Budiman Hakim. 2010. Dampak Pengembangan Perkebunan Kelapa RakyatTerhadap Kemiskinan dan
Perekonomian di Kabupaten Indragiri Hilir. Jurnal Agro Ekonomi, 28 (1): 69-94

Budiharsono, S. 2001. Teknik Analisis Pembangunan Wilayah Pesisir dan Lautan. Pustaka Sains dan Teknologi. Pradnya Paramita. Jakarta.

Damanik, S. 2007. Strategi Pengembangan Agribisnis Kelapa (Cocos nucifera) untuk Meningkatkan Pendapatan Petani di Kabupaten Indragiri Hilir, Riau.perspektif, 6 (2): 94-104.

Kristiana, L. 2014. Analisis Strategi Pengembangan Agribisnis Kelapa Sebagai Komoditas Unggulan di Kecamatan Cidaun, Kabupaten Cianjur. AGROSAINS,01 (01): 1-12

Nazir, M. 2009. Metode Penelitian. Ghalia Indonesia, Jakarta.

Pongi, S. Y., Made Antara., Mahfudz., Rustam. 2015. Superior Commodities Potential and the Strategy Development in Sigi District, Central Sulawesi Province. International Journal of Business and Management Invention, 4 (11): 23-30.

Prawoto, N. 2010. Pengembangan Potensi Unggulan Sektor Pertanian. Jurnal Ekonomi dan Studi Pembangunan, Vol 11(1); 1-19

Rangkuti, F. 2009. Analisis SWOT Teknik Membedah Kasus Bisnis. PT Gramedia Pustaka Utama, Jakarta.

Ruslan, S. 1986. Peranan Subsektor Perkebunan Khususnya Kelapa Dalam Pembangunan Daerah Kabupaten Selayar Propinsi Sulawesi Selatan. Tesis Pascasarjana IPB. Bogor (Tidak dipublikasikan).

Tripomo, T. Udan. 2005. Manajemen Strategi. Rekayasa Sains. Bandung.

Warpani, S. 1984. Analisis Kota dan Daerah. Penerbit ITB, Bandung

Vaulina, S., DAN Khairizal. 2016. Identifikasi Komoditi Unggulan pada Sektor Pertanian di Kabupaten Indragiri Hilir Propinsi Riau. Jurnal Agribisnis, 18 (1): 42-54.

Zulgani. 1994. Peranan Produksi Kelapa Dalam Pengembangan Ekonomi Wilayah Kabupaten Tanjung Jabung. Tesis Magister Pertanian Program Pascasarjana. Universitas Padjadjaran. (Tidak dipublikasikan). 
